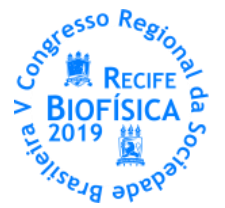

\title{
CONSEQUÊNCIAS DA RESTRIÇÃO DO CAMPO VISUAL SUPERIOR
}

\author{
Humberto Dória Silva ${ }^{1 *}$, Eduardo Dória Silva ${ }^{1}$, Maria Tamires Dória Silva², Cristiana Pereira Dória² \\ ${ }^{1}$ UFPE; ${ }^{2}$ Profissional liberal \\ *hdoria@ufpe.br
}

\begin{abstract}
INTRODUÇÃO
Em 2011 foi criado, no CNPq, o grupo de pesquisa "Transferência de massa em meio poroso flexível", com o objetivo de analisar o mecanismo de transferência de massa intraocular, por convecção forçada, para fortalecer o trabalho analítico de recuperação física da visão humana, que estava sendo desenvolvido, pelo primeiro autor, desde 1998.

Neste trabalho é demonstrado, como a restrição do campo visual superior, pode estimular diversas patologias oculares, inclusive, causar linhas de expressão, além de recomendar a realização do procedimento cirúrgico de elevação do supercílio, como cirurgia plástica corretiva, a partir do depoimento de um paciente entrevistado.
\end{abstract}

\section{MATERIAIS E MÉTODOS}

A equipe realizou estudo bibliográfico dos sintomas descritos nas entrevistas realizadas com diversos amigos e colegas, além das percepções do primeiro autor, durante o período de recuperação de sua visão. Não há necessidade do parecer do comitê de ética, porque não foi necessário qualquer procedimento invasivo e os exercícios foram realizados sob a responsabilidade da própria pessoa.

Na normalidade ocular, o olho tem os movimentos de adução e abdução, em torno do eixo vertical, sursundução e deorsundução, em torno do eixo transversal (Bicas H. E. A., 2003) e acomodação da córnea, para fazer a fusão das imagens, (Silva H. D. et al., 2018). Este último movimento produz as condições físicas, para transferência de massa, por meio da convecção forçada intraocular, que agita e uniformiza as concentrações dos compostos da massa móvel, estimulado pelo processamento das imagens que chegam ao cérebro. A falha, deste movimento, causa acúmulo dos resíduos metabólico, provoca aglutinações dos resíduos, por desidratação, e, em consequência, modifica a refração intraocular, criando patologias oculares em forma de sintomas (entre outros, miopia e astigmatismo), geometria (formato ocular) e movimentos, (exciclodução ou extorção e de inciclodução ou intorção em torno do eixo longitudinal ou anteroposterior (Bicas H. E. A., 2003, Silva H. D. et al., 2019)).

Ptose palpebral é uma alteração anatômica caracterizada pelo posicionamento da pálpebra superior abaixo de sua posição normal, que está localizada cerca de $2 \mathrm{~mm}$ abaixo do limbo superior na posição primária do olhar, (Lucci L. M. D. et al., 2009). É uma afecção palpebral bastante frequente, podendo gerar problema estético e também funcional, à medida que produz restrição do campo visual superior ou oclusão do eixo visual, levando a posição viciosa de cabeça e pescoço, (Carregal T. B. et al., 2012).

A ptose do supercílio é alteração frequente, porém geralmente subdiagnosticada. A melhor maneira de definir a ptose do supercílio é quando ele se encontra abaixo do rebordo orbitário (Schmit G. L. et al. 2011).

Exposição do sofrimento de um paciente: 0 paciente procurou um oftalmologista porque estava com redução da abertura da fenda palpebral. 0 médico explicou, condicionando, o trabalho, ao custeamento da cirurgia para elevação do supercílio, e, em seguida, realizar a blefaroplastia, porque o plano de saúde considera como estética, a cirurgia de elevação do supercílio. 0 paciente procurou outro profissional que realizou a cirurgia de ptose palpebral em abril de 2016. Após dois anos e dez meses, o paciente procurou outro oftalmologista para mostrar a restrição do seu campo visual superior. 0 oftalmologista solicitou e o plano de saúde aprovou o procedimento cirúrgico "supercílio reconstrução total", código 30301220. O paciente aguarda a realização do procedimento.

\section{RESULTADOS E DISCUSSÃO}

As imagens projetadas nas retinas são utilizadas para o controle ocular da estereopsia e projetar o ponto de fixação nas fóveas. Este controle produz constantes movimentos oculares que provocam agitação e favorece a transferência de massa, por convecção forçada, dos meios móveis da córnea, do cristalino e da retina. A ptose congênita e a ptose adquirida prejudicam as projeções das imagens nas retinas, logo, provoca falhas nos movimentos de agitação e transferência de massa, e, consequentemente, acumula resíduos metabólicos, nas regiões ocluídas, da córnea, do cristalino e da retina, causando erros de refração, entre muitas outras patologias. A ptose palpebral adquirida pode ser resultante da oclusão lenta, gradual e involuntária, da região superior da pupila, para reduzir as refrações patológicas intraocular, promovida pelo acúmulo de resíduos metabólicos intraoculares, ou pela restrição do campo visual superior (queda de supercílio). A queda de supercílio, pode impede a passagem da luz através da córnea, e causar, inicialmente e inconscientemente, movimentos constantes e repetitivos, do músculo frontal (testa), para elevação do supercílio quando há redução o empecilho à passagem luminosa. Naturalmente, provoca rugas, dinâmicas ou de repouso. A ptose congênita e a ptose adquirida podem ocorrer de forma combinada com a queda de supercílio. Neste caso, a pálpebra superior, além de sua borda ficar situada abaixo da posição normal, ela recebe um material adicional procedente do supercílio. Naturalmente, a cirurgia de levantamento da pálpebra é insuficiente para solucionar a patologia, principalmente, se o paciente apresentar rugas frontais, que são oriundas dos esforços inconscientes, para restabelecer a amplitude do campo visual superior. 


\section{CONCLUSÕES}

A eliminação da causa, seguramente, elimina os efeitos, ou seja, a cirurgia de elevação do supercílio, para recuperar o campo visual superior, certamente, reduzirá e até eliminará as rugas da testa, mas, a eliminação ou redução das rugas, não pode ser o critério para considerar a cirurgia como estética. A queda do supercílio quando ele se encontra abaixo do rebordo orbitário, aliada as rugas da testa é, conforme a exposição, suficiente para a cirurgia "supercílio - reconstrução total", código 30301220, independente da ptose palpebral, para retirada da massa depositada sobre a pálpebra superior e recuperar a perda do campo visual superior, evidenciada pela formação das rugas. Logo após a cirurgia do supercílio, pode incluir a blefaroplastia, se borda da pálpebra superior estiver abaixo da posição normal.

\section{AGRADECIMENTOS}

Em primeiro lugar a Deus, por ter ajudado o primeiro autor nos longos anos de sofrimentos, causados pelo médico, que recomendou a viagem de avião sua mãe, 15 dias antes do nascimento do paciente, que o levou a ser um analítico observador dos eventos em seu próprio corpo. Em adição, por ajudar a todos coexistir, durante os danos causados pelas decisões políticas e econômicas do país. Ao Marcos, irmão dos dois primeiros autores, que, em 1999, mostrou a importância do relaxamento oculomotor para o tratamento da vista, em um livro de autoajuda. Aos colegas, dos dois primeiros autores, membros do ANDES-SN Sindicato Nacional e, também, aos colegas membros da Seção Sindical ADUFEPE, que, durante os intervalos dos encontros sindicais, proveu importantes ajudas científicas para a pesquisa. A todos os amigos, colegas e membros da família entrevistados que contribuíram direta ou indiretamente para pesquisa. Nenhuma instituição pública ou privada participou com ajuda financeira, para a publicação deste trabalho. Todos os autores concordam com os agradecimentos.

\section{REFERÊNCIAS}

Bicas H. E. A., Oculomotricidade e seus fundamentos, Arq. Bras. Oftalmol. 2003;66:687-700

Carregal T. B., et al., Ptose palpebral: avaliação do posicionamento palpebral por imagens digitais, Ver. Bras. Oftalmol. 2012; 71 (1): 18-22.

Schmit G. L., et al., Correção da ptose da sobrancelha por via transpalpebral associada a retalho periostal, Rev. Bras. Cir. Plást. 2011; 26(supl): 1-102.

Lucci L. M. D., et al., Transposição da rima palpebral em ptose miogênica mitocondrial,ArqBras Oftalmol. 2009;72(2):159-63.

Silva H. D., et al., Analysis of the Disturbances Caused by Intraocular Forced Convection Mechanism Failure, Capítulo 3, Zilfyan A., Livro, Difficulties in Cataract Surgery, IntechOpen, Londres, 2018,3:45-64,.

Silva H. D., et al., Movimento oculomotor e algumas patologias, Capítulo 4, Sabrina P. M., Livro Teorias e métodos da biofísica [recurso eletrônico], Ponta Grossa - PR, Atena Editora, 2019, 3642 , 